\section{Quality improvement of prescribing safety: a pilot study in primary care using UK electronic health \\ records}

We agree with Booth et al that pharmacists in general practice could have an important role in actioning reports from electronic health records. We look forward to the impact evaluation that will assess alterations in prescribing because of this initiative.

In addition to identifying potentially unsafe prescribing, interrogation of electronic health records can also be used to identify patients who are not prescribed appropriate medication for their condition, and are at risk of harm through untreated disease. We have previously reported about the activities of general practice pharmacists in Canberra, Australia, ${ }^{2}$ one of whom conducted an audit using electronic health records to identify patients diagnosed with atrial fibrillation (AF) in a single general practice during 2016. Three untreated patients were identified: if they had been treated with warfarin, this would have saved them 1.38 years of life and prevented 0.56 strokes over 5 years. ${ }^{3}$ The total value of the intervention was estimated to be $\$ 157360$ (\$28 620-\$244 310) over 5 years ladjusted to 2016 values when the intervention occurred) [calculated by the author from Australian Institute of Health and Welfare data] ${ }^{4,5}$

Our findings support the regular interrogation of general practice electronic health records, not only to improve patient safety but also to contribute to the sustainability of health provision.

Sam Kosari,

Pharmacist Lecturer, University of Canberra, Bruce, ACT, Australia.

Email: sam.kosariacanberra.edu.au

Louise S Deeks,

Pharmacist Researcher, University of Canberra, Bruce, ACT, Australia.

John Goss,

Health Economist, University of Canberra, Bruce, ACT, Australia.

Mark Naunton,

Professor of Pharmacy, University of
Canberra, Bruce, ACT, Australia.

\section{REFERENCES}

1. Booth HP, Gallagher AM, Mullett D, et al. Quality improvement of prescribing safety: a pilot study in primary care using UK electronic health records. Br J Gen Pract 2019; DOI: https://doi.org/10.3399/ bjgp19X704597.

2. Deeks LS, Naunton M, Tay GH, et al. What can pharmacists do in general practice? A pilot. Aust J Gen Pract 2018; 47(8): 545-549. DOI: 10.31128/ AJGP-03-18-4520.

3. Hart RG, Benavente O, McBride R, Pearce LA. Antithrombotic therapy to prevent stroke in patients with atrial fibrillation: a meta-analysis. Ann Intern Med 1999; 131(7): 492-501.

4. Australian Institute of Health and Welfare. Healthcare expenditure on cardiovascular diseases 2008-09. Cat. no. CVD 65. Canberra: AlHW, 2014.

5. Australian Institute of Health and Welfare. Cardiovascular disease, diabetes and chronic kidney disease - Australian facts: prevalence and incidence. Cardiovascular, diabetes and chronic kidney disease series no. 2. Cat. no. CDK 2. Canberra: AlHW, 2014

DOI: https://doi.org/10.3399/bjgp19X705725

\section{High results}

Thank you for your article highlighting the need to intelligently think about what tests we request rather than just tick boxes.' The summary states that 'Inflammatory markers ... should not be used as rule-out tests. However, I think that the print version of the article short-changes the reader since, in your online version, it is clear that high levels of CRP and ESR are associated with important disease in a third of cases. This is surely something that ought to have been highlighted and would I think merit a softer conclusion.

\section{Tim D Caroe,}

GP, Lighthouse Medical Practice,

Eastbourne.

Email: timcaroelanhs.net

\section{REFERENCE}

1. Watson J, Salisbury C, Whiting P, et al. Added value and cascade effects of inflammatory marker tests in UK primary care: a cohort study from the Clinical Practice Research Datalink. Br J Gen Pract 2019; DOI: https://doi.org/10.3399/bjgp19X704321.

\section{Authors' response}

There are two important clinical questions for GPs: first, when should they use inflammatory marker tests, and, second, how should they interpret results?

The answer to the first question relates to the sensitivity and specificity of the tests, which determine whether they are useful to rule out or rule in respectively. We state that Inflammatory markers ... should not be used as a rule-out test' because, with an overall sensitivity of $<50 \%$, they are normal, and would therefore 'miss' around half of those patients with relevant pathology. The reason for highlighting this message is that it is in direct contradiction to our previous qualitative research, which suggests that GPs tend to use inflammatory markers as a non-specific 'rule-out' test.'

The second question, about how to interpret results, depends on the positive land negative) predictive value of the tests; overall $15 \%$ of those with a positive test were found to have some relevant pathology and this figure rises, unsurprisingly, with higher test results. We agree that this is also an important finding and we hope that Figures $3-5$ in the online version of the article will be useful for clinicians trying to interpret a raised inflammatory marker, allowing them to determine the likelihood of disease in relation to inflammatory marker levels.

\section{Jessica Watson,}

GP and NIHR Doctoral Research Fellow, University of Bristol, Bristol.

Email: jessica.watsonabristol.ac.uk

Chris Salisbury,

Professor of Primary Health Care, University of Bristol, Bristol.

Jonathan Banks,

Research Fellow, University of Bristol, Bristol.

Penny Whiting,

Associate Professor in Clinical Epidemiology, University of Bristol, Bristol.

Willie Hamilton,

Professor of Primary Care Diagnostics, University of Exeter, Exeter.

\section{REFERENCE}

1. Watson J, de Salis I, Hamilton W, Salisbury C. I'm fishing really' - inflammatory marker testing in primary care: a qualitative study. Br J Gen Pract 2016; DOI: https://doi.org/10.3399/bjgp16X683857.

DOI: https://doi.org/10.3399/bjgp19X705749 